\title{
Role of ultrasound in detection of radiolucent foreign bodies in extremities
}

\author{
Mehraj D. Tantray $^{1} \cdot$ Asim Rather $^{2} \cdot$ Qazi Manaan $^{1} \cdot$ Irfan Andleeb $^{1} \cdot$ Mir. Mohammad $^{1} \cdot$ Yasmeena Gull $^{3}$
}

Received: 8 March 2017 / Accepted: 30 January 2018 / Published online: 9 February 2018

(c) The Author(s) 2018. This article is an open access publication

\begin{abstract}
Removal of foreign bodies from soft tissues in emergency is very challenging and becomes more problematic when it is radiolucent. Blind exploration is sometimes hazardous for patients especially when it is in proximity to a vessel or a nerve or an overlying tendon. The purpose of this study was to determine the accuracy of ultrasonography (USG) in detecting radiolucent soft tissue foreign bodies in the extremities. From January 2014 to January 2016, 120 patients with either a positive history or clinically suspected soft tissue foreign body and negative radiography were evaluated by USG with a high-frequency (13-6 MHz) linear-array transducer. The sonographic findings were used to guide surgical exploration. Out of 120 patients who underwent surgical exploration, USG was positive in 114 cases, and foreign body was retrieved in 108 cases, and among the six cases where USG was negative, foreign body was retrieved from one case. In one case with strong clinical suspicion of foreign body USG was falsely negative. Majority of foreign bodies were removed from foot (69 cases) and hands ( 26 cases), and rest of foreign bodies were removed from ankle ( 4 cases), wrist ( 3 cases), thigh ( 2 cases), leg ( 1 case), knee ( 2 cases), forearm ( 2 cases). Accuracy, sensitivity, and positive predictive value were determined as 94.16 , 99.08 , and $94.13 \%$, respectively. The real-time high-frequency USG is a highly sensitive and accurate tool for detecting and removing radiolucent foreign bodies which cannot be visualized by routine radiography.
\end{abstract}

Keywords Extremities $\cdot$ Foreign body $\cdot$ Radiolucent $\cdot$ Ultrasonography

Mehraj D. Tantray

drmehraj8916@gmail.com

Asim Rather

asimrather@yahoo.co.in

Qazi Manaan

q.manaan@gmail.com

Irfan Andleeb

irfangul34@gmail.com

Mir. Mohammad

mirmohd@live.com

Yasmeena Gull

dryasmeengul@gmail.com

1 Department of Orthopaedics, Bone and Joint Hospital, Barzulla, GMC, Srinagar, Jammu and Kashmir 190005, India

2 Department of Radiognosis, GMC, Srinagar, Jammu and Kashmir, India

3 Department of Health and Family Welfare J\&K Health Services India, Srinagar, India

\section{Background}

Penetrating foreign bodies are common in patients visiting emergency departments [1,2]. Farming being the most common job among the population in Kashmir with practice of working bare footed in orchards, the probability of penetration of tree splinters as a radiolucent foreign body in the extremities, especially the sole of the foot, is high. The missed foreign body may remain asymptomatic for prolonged periods or else lead to a wide range of complications including pain, abscess, chronic discharging wound, necrotizing fasciitis bone and joint destructive lesions granulomas with impairment of tendon mobility or triggering of digits migration delayed tendon ruptures, neurodeficits, pyogenic granulomas, vascular events, massive soft tissue injury, and lawsuits [3-15].

A radiolucent foreign body such as wood frequently remains undetected [16]. Sonography plays an important role in the evaluation of these patients [17].

Sonography has a reported sensitivity of $95 \%$ for detection of foreign bodies $[18,19]$. 
In previous reports the positive predictive value of conventional radiography (CR) and sonography (US) were 100 and $95 \%$, respectively, and for computed tomography (CT), and magnetic resonance imaging (MRI) were 95 and $93.8 \%$, respectively. CT had a negative predictive value of $78.3 \%$, while US, MRI, and CR had 73.7, 70.1, and 53.7\%, respectively [20].

Non-opaque foreign bodies are visualized as hyper-echoic foci with accompanying acoustic shadows [17]. A hypoechoic halo surrounding the foreign body is sometimes seen, which represents edema, abscess, or granulation tissue [21].

The purpose of the study was to determine effectiveness of sonography for detection of radiolucent foreign bodies and to summarize the experiences using sonography in the management of patients with a suspected retained foreign body.

\section{Materials and methods}

From January 2014 to January 2016, 120 symptomatic patients with definite history and clinical suspicion of soft tissue foreign body and negative radiography were included in the study. A single radiologist who had 6 years of experience in the radiology department received the radiographs and carried out the sonographic examination. All ultrasound examinations were carried out on a sonosite Micro$\operatorname{maxx}$ USG machine using high-frequency (13-6 MHz) linear-array transducer. USG scans were performed in multiple planes as required according to the part being examined. After location of the soft tissue foreign body, its size, depth, and orientation were documented. Relationship to other structures such as muscles, tendon, bone, and vessels were determined. Doppler mode was also employed wherever deemed necessary. Any associated abscess, granuloma, or cellulitis were evaluated. A single orthopedic surgeon carried out direct surgical exploration guided by sonographic findings. Sensitivity of USG was determined with respect to the findings on surgical exploration (Fig. 1).

\section{Results}

One hundred and twenty patients underwent surgical exploration; among them 114 patients had a positive USG, and foreign body was retrieved from 108 patients, and in the rest of six patients in whom USG was positive, five had underwent at least one previous exploration. Among the six patients in whom USG was negative, one patient with strong suspicion of foreign body had chronic discharging sinus near tendo Achilles insertion, and a thorn was removed on exploration. Ninety patients $(75 \%)$ were males and $30(25 \%)$ were females. Mean age of the patients was 27.6 years (range 6-70 years). Duration of the patients' complaint was from 1 day to 4 years, while in $50 \%$ of cases, it was less than a month. Predominant chief
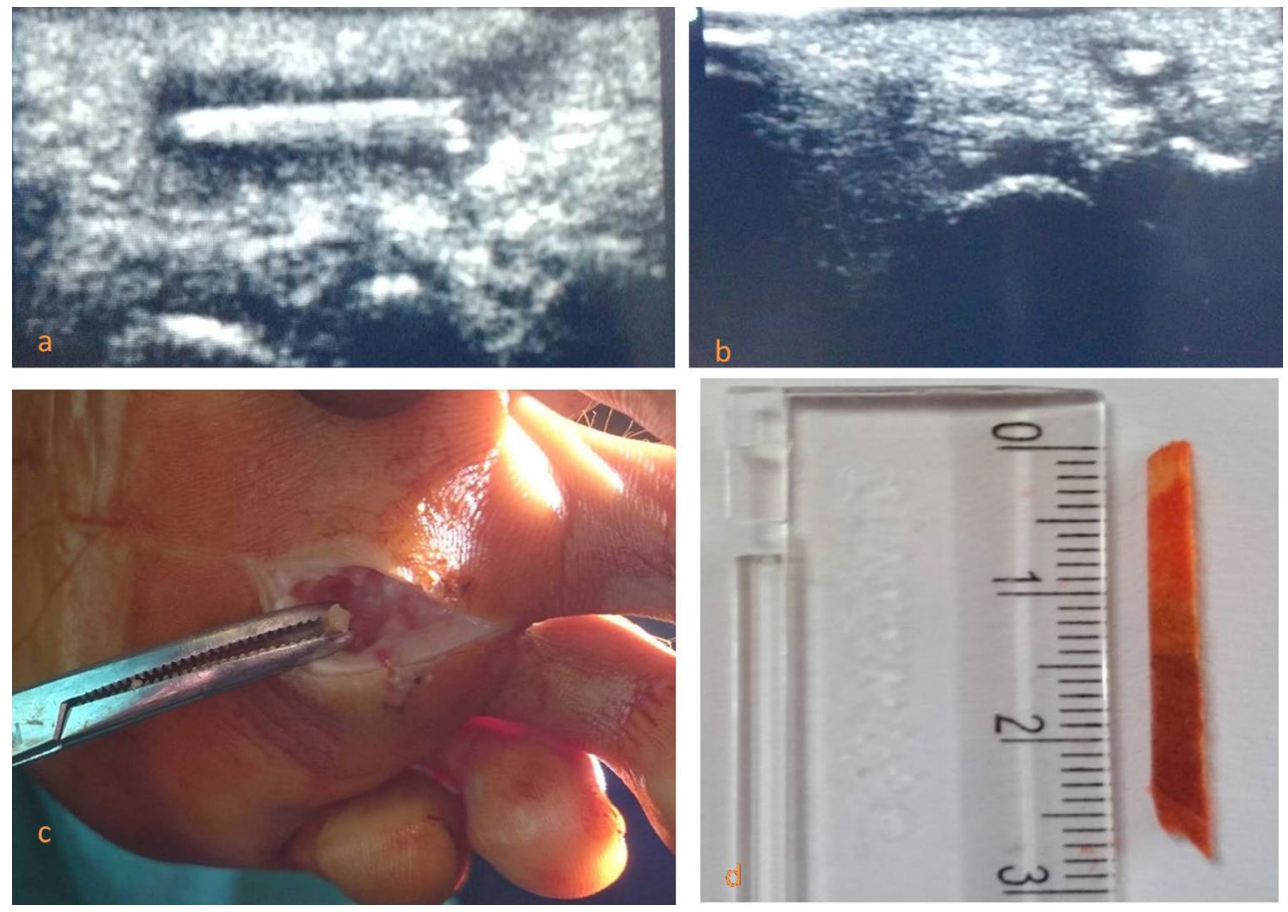

Fig. 1 Ultrasound of foot of the patient with chronic discharging sinus (a \& b). Surgical removal (c) and wood foreign body (d) 
Table 1 Site of foreign body removal in order of frequency

\begin{tabular}{lc}
\hline $\begin{array}{l}\text { Site of foreign } \\
\text { body removal }\end{array}$ & No. of cases \\
\hline Foot & 69 \\
Hands & 26 \\
Ankle & 4 \\
Wrist & 3 \\
Thigh & 2 \\
Leg & 1 \\
Knee & 2 \\
Forearm & 2 \\
Total & 109 \\
\hline
\end{tabular}

Table 2 Types of foreign bodies recovered

\begin{tabular}{lc}
\hline Nature of foreign body & $\begin{array}{c}\text { Number } \\
\text { of cases }\end{array}$ \\
\hline Wooden & 41 \\
Thorn & 38 \\
Rubber/plastic/nail slipper & 22 \\
Glass & 08 \\
Total & 109 \\
\hline
\end{tabular}

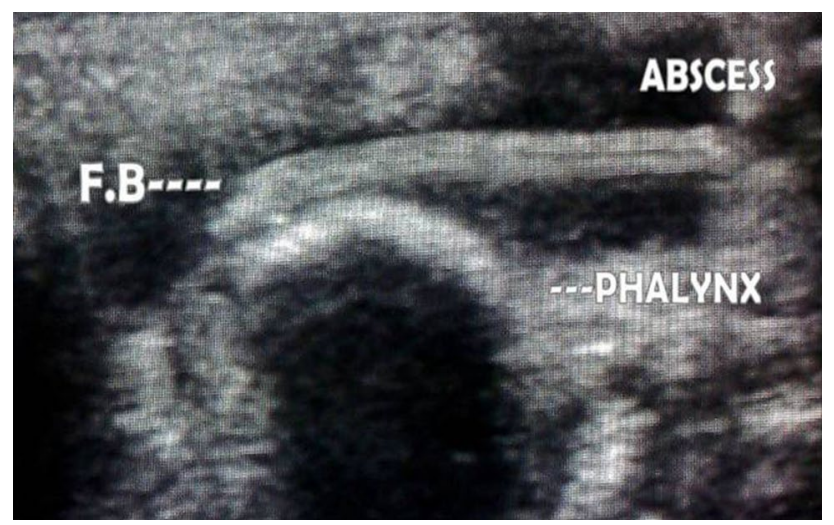

Fig. 2 Ultrasound of hand showing foreign body with abscess formation on dorsum of hand

complaints of the patients were: foreign body sensation in $49(40.83 \%)$, abscess formation in $38(31.66 \%)$, discharging wound in $19(15.83 \%)$, and pain in $14(11.66 \%)$ cases. Foreign bodies removed were wooden (41 cases), thorn (38 cases), rubber/plastic from nail slipper ( 22 cases), and glass ( 8 cases). Majority of foreign bodies were removed from foot (69 cases) and hands ( 26 cases), and rest of foreign bodies were removed from ankle region (4 cases), wrist ( 3 cases), thigh ( 2 cases), leg ( 1 case), knee ( 2 cases),

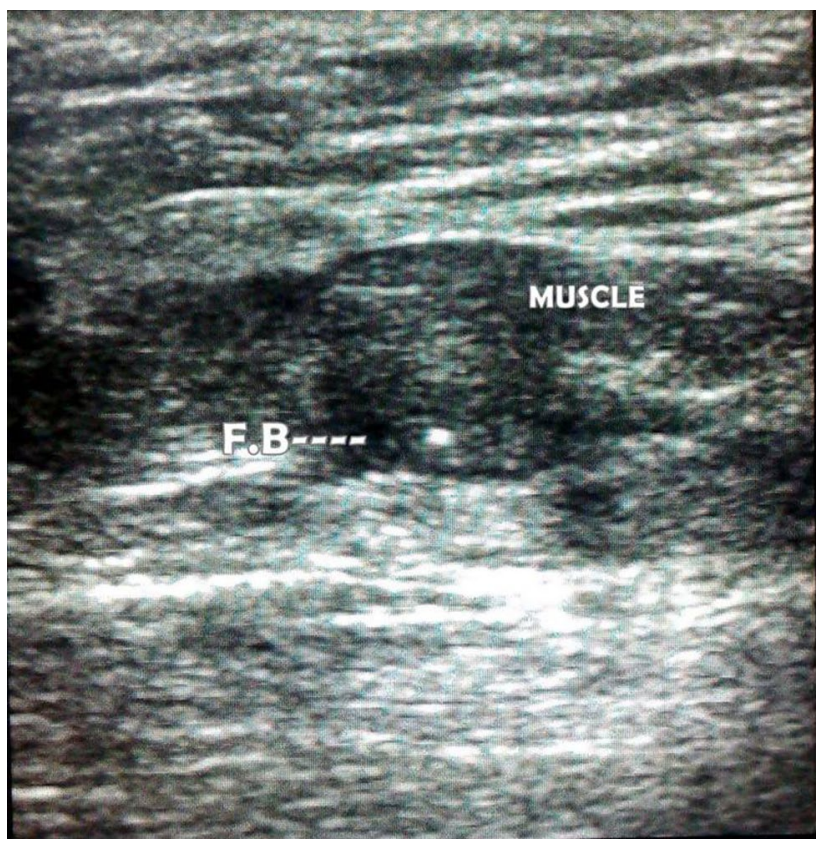

Fig. 3 Ultrasound of calf showing foreign body within the muscle

forearm ( 2 cases) (Tables 1,2$)$. Size of the foreign body varied between 3 to $32 \mathrm{~mm}$ with mean of $15 \mathrm{~mm}$ (Fig. 2).

The accuracy, sensitivity, and PPV of this study were 94.16, 99.08, and 94.13\%, respectively (Fig. 3).

\section{Discussion}

Conventional radiographs should be obtained to rule out the presence of radio-opaque foreign objects. Plain radiographs will depict approximately $80 \%$ of all foreign bodies, but several types of radiolucent foreign bodies such as wood remain undetected [22]. Plain radiographs of wooden FB are negative in $86 \%$ of such patients [23]. In these patients, sonography is the modality of choice for identification of such radiolucent foreign body.

The identification of wooden foreign bodies may be difficult on MRI, especially when foreign bodies are small, and there is no associated abscess, granulation tissue, or fluid collection. In such cases, the foreign body may appear as a signal void with surrounding nonspecific granulation tissue. Wooden foreign bodies may be seen signal void in all sequences, but after water absorption, it could be seen hypo-intense on $\mathrm{T} 1$ and hyper-intense on $\mathrm{T} 2$ images [17]. When compared with Sonography, MRI is more expensive, less readily available, and has less value in the detection of small wooden foreign bodies.

Sonographic evaluation provides important information on the depth, size, and anatomical relationship with surrounding structure $[18,21,24]$. Although CT has 
sensitivity 5-15 times greater than that of plain X-ray, it is not as sensitive as US, or MRI [25]. Additionally, the expense, use of radiation, and availability make the use of CT less than optimal in the clinical setting.

Out of 120 patients, USG was positive in 114 patients, and foreign body was retrieved from 108 patients, and in six patients for whom USG was falsely positive, five had underwent at least one previous surgical exploration, whereas among the six patients in whom USG was negative, foreign body was retrieved in one patient who had chronic discharge near ankle region. Detection of foreign body is difficult in interphalangeal space and in air-contaminated tissue after a penetrating trauma. FB must be distinguished from hyper-echoic body tissue such as ossified cartilage sesamoid bones, scar tissue, gas bubble, and intermuscular fascia. Acoustic shadowing is an important clue in the differential diagnosis [18, 21]. Acoustic shadowing can differentiate foreign body from scar tissue, gas bubble, and normal intermuscular fascia, because they are void of acoustic shadowing.

Our results demonstrate the effectiveness of sonography for detection of radiolucent FB. It is therefore an important and easily available modality that facilitates removal of the object by reducing the blind explorations and chances of iatrogenic tissue damage.

Peterson et al. [17] showed that sonography is the modality of choice in patients who present with a history of antecedent skin puncture or when a penetrating injury is suspected.

Dumarey et al. [26] showed that CT gave a good anatomic overview, but was not able to show the smaller fragments. Performing sonography is mandatory in patients with penetrating injuries by foreign bodies because it is very sensitive.

We believe that all foreign bodies were seen during sonographic examination as echogenic objects, and most of them (wooden, glass, etc.) may also show similar sonographic findings.

Foreign bodies in the extremities are a common complaint in agrarian populations. Most of these patients have normal X-rays as these foreign bodies being radiolucent. Ultrasonography being readily available and cheap modality could be a very useful tool to confirm the presence of foreign body, determine its depth, size and proximity to adjoining nerve, vessel, or a tendon. This will minimize the false-negative surgical explorations and prevent damage to adjoining structures. Although pre-op CT scan or MRI could be the better option but considering the availability and financial constrains especially in developing and underdeveloped nations, ultrasonography seems to be a useful tool to aid in exploration. Because of lack of comparison, we cannot recommend USG over CT scan or MRI, and this could be the possible limitation of our study.

\section{Compliance with ethical standards}

Conflict of interest The authors declare that they have no conflict of interest.

Ethical approval All the procedures performed in the study were in accordance with the ethical standards of the regional national research committee and with the 1964 declaration of Helsinki and its later amendments and comparable ethical standards.

Informed consent The informed consent was taken from all the participants included in this study.

Open Access This article is distributed under the terms of the Creative Commons Attribution 4.0 International License (http://creativeco mmons.org/licenses/by/4.0/), which permits unrestricted use, distribution, and reproduction in any medium, provided you give appropriate credit to the original author(s) and the source, provide a link to the Creative Commons license, and indicate if changes were made.

\section{References}

1. Boyse TD, Fessell DP, Jacobson JA, Lin J, van Holsbeeck MT, Hayes CW (2001) US of soft-tissue foreign bodies and associated complications with surgical correlation. Radiographics 21:1251-1256

2. Saki N, Nikakhlagh S, Rahim F, Abshirini H (2009) Foreign body aspirations in infancy: a 20-year experience. Int J Med Sci 6:322-328

3. Borgohain B, Borgohain N, Nandique A, Gogoi PJ (2012) Case report and brief review of literature on sonographic detection of accidentally implanted wooden foreign body causing persistent sinus. Crit Ultrasound J 4:10

4. Yanay O, Vaughan DJ, Diab M, Brownstein D, Brogan TV (2001) Retained wooden foreign body in a child's thigh complicated by severe necrotizing fasciitis: a case report and discussion of imaging modalities for early diagnosis. Pediatr Emerg Care 17:354-355

5. Fakoor M (2006) Prolonged retention of an intra-medullary wooden foreign body. Pak J Med Sci 22:78-79

6. Freund EI, Weigl K (1984) Foreign body granuloma: a cause of trigger thumb. J Hand Surg Br 9:210

7. Choudhari KA, Muthu T, Tan MH (2001) Progressive ulnar neuropathy caused by delayed migration of a foreign body. Br J Neurosurg 15:263-265

8. Yang SS, Bear BJ, Wieland AJ (1995) Rupture of the flexor pollicis longus tendon after 30 years due to migration of a retained foreign body. J Hand Surg Br 20:803-805

9. Jablon M, Rabin SI (1988) Late flexor pollicis longus tendon rupture due to retained glass fragments. J Hand Surg Am 13:713-716

10. Rainer C, Schoeller T, Wechselberger G, Bauer T, Hussl H (2000) Median nerve injury caused by missed foreign body. Scand J Plast Reconstr Surg Hand Surg 34:401-403

11. Azzopardi EA, Xuereb CB, Iyer S (2009) Pyogenic granuloma as a surrogate indicator of deep seated foreign bodies: a case report. Cases J 2:7354

12. James W, Robert A, Suzanne M (1995) Vascular complications of a foreign body in the hand of an asymptomatic patient. Ann Plast Surg 34:92-94

13. Meurer WJ (2009) Radial artery pseudo aneurysm caused by occult retained glass from a hand laceration. Pediatr Emerg Care 25:255-257 
14. Coombs CJ, Mutimer KL, Slattery PG, Wise AG (1990) Hide and seek: pre-operative ultrasound localization of non-radio-opaque foreign bodies. Aust N Z J Surg 60:989-991

15. Dunn JD (1987) Risk management in emergency medicine. Emerg Med Clin N Am 5:51-69

16. Graham DD Jr (2002) Ultrasound in the emergency department: detection of wooden foreign bodies in the soft tissues. J Emerg Med 22(1):75-79

17. Peterson JJ, Bancroft LW, Kransdorf MJ (2002) Wooden foreign bodies: imaging appearance. AJR Am J Roentgenol 178(3):557-562

18. Crowford R, Matheson AB (1989) Clinical value of ultrasonography in detection and removal of radiolucent foreign bodies. Injury 20:341-343

19. Ober CP, Jones JC, Larson MM, Lanz OI, Werre SR (2008) Comparison of ultrasound, computed tomography, and magnetic resonance imaging in detection of acute wooden foreign bodies in the canine manus. Vet Radiol Ultrasound 49(5):411-418
20. Venter NG, Jamel N, Marques RG, Djahjah F, MendonçaLde S (2005) Evaluation of radiological methods for detection of wood foreign body in animal model. Acta Cir Bras 20(Suppl 1):34-41

21. Little CM, Parker MG, Callowich MC, Sartori JC (1986) The ultrasonic detection soft tissue foreign bodies. Investig Radiol 21:275-277

22. Donaldson J (1991) Radiographic imaging of foreign bodies in the hand. Hand Clin 7:125-134

23. Anderson MA, Newmeyer WL, Kilgore ES (1982) Diagnosis and treatment of retained foreign bodies in the hand. Am J Surg 144:63-67

24. Conti RJ, Shinder M (1991) Soft tissue calcification induced by local corticosteroid injection. J Foot Surg 30:34-37

25. Flom LL, Ellis GL (1992) Radiologic evaluation of foreign bodies. Emerg Med Clin North Am 10:163-176

26. Dumarey A, De Maeseneer M, Ernst C (2004) Large wooden foreign body in the hand: recognition of occult fragments with ultrasound. Emerg Radiol 10(6):337-339 